\title{
Differences between Chemical and Physical Disulfide Blocking of Whey Proteins Aggregates. Investigation Using Dilute Solution Viscometry
}

\author{
Ahmed S. EISSA \\ Department of Chemical Engineering, Cairo University, Cairo, Egypt, 12613
}

\begin{abstract}
Thermal aggregation of whey proteins has been the topic of extensive research work. Blocking of disulfide bonds is quite important for the understanding of aggregation mechanism and, specifically, the role of disulfide interchange reaction. In this work, chemical blocking of disulfide bonds by Dithiothreitol (DTT) was compared with physical blocking (at pH 3), when molecules at both conditions were subjected to thermal aggregation at $80^{\circ} \mathrm{C}$ for $1 \mathrm{hr}$. Results indicate differences in molecular properties at the two aggregation conditions. Aggregates that were formed via thermal treatment in the presence of chemical blocking reagents (DTT) produced larger aggregates of spherical, collapsed macromolecules. However, aggregate formed when disulfide bonds were physically blocked - at $\mathrm{pH}$ 3- produced smaller aggregates of spherical, wormlike macromolecules.

Keywords: whey proteins, dilute solution viscometry, disulfide.
\end{abstract}

\section{INTRODUCTION}

Whey proteins offer rich nutritional and functional properties in food products. Functional properties of whey proteins result from the physical and chemical interactions that form the three dimensional distinguished configuration of the molecules. Gelation, emulsification, foaming and thickening represent the main functional properties of whey proteins. Disulfide bonds are the major chemical bonds that cause protein polymerization and gelation upon thermal treatment at a temperature above the denaturation temperature for various proteins, including whey proteins [1]. Disulfide bonds in native proteins cause protein stabilization [2]. However, upon heat treatment, protein is destabilized and disulfide interchange reaction proceeds to form higher molecular weight protein molecules.

Disulfide bonds are frequently used to investigate protein structure and stability [3]. The assessment of the role of disulfide bonds in whey proteins is best practiced by blocking the disulfide bonds and comparing the blocked protein system with the unblocked one. Blocking of disulfide bonds can be done chemically by different chemical reagents such as dithiothreitol (DTT), $\beta$-mercaptaethanol $(\beta$-ME) N-ethylmaleimide (NEM)

(Received 19 Apr. 2016: accepted 12 May. 2016)

$\dagger$ Fax: +202-35728232, E-mail: aseissa@gmail.com

This manuscript has not been published elsewhere and it has not been submitted for publication elsewhere and others.

Disulfide-reducing reagents reduce the native disulfide bonds in proteins and maintain the essential thiol groups in proteins by preventing their oxidation to the disulfide state.

In addition, the thiol group can be reduced under acidic conditions. For example, whey proteins at $\mathrm{pH}$ values lower than 4 are not capable of forming disulfide bonds because of thiol group reduction [4].

DTT possess high conformational propensity to form a six membered ring, in which the disulfide bond is part of the ring. DTT is frequently used to reduce the disulfide bonds of proteins and, more generally, to prevent intermolecular disulfide bonds from forming between cysteine residues of proteins.

The literature lacks any dedicated comparison between physical and chemical blocking of disulfide interchange reaction.

In this work, we utilize dilute solution viscomtery (DSV) to probe the molecular properties of protein aggregates in dilute solutions to characterize the differences between physical and chemical blocking of disulfide interchange reaction over temperature range from $30^{\circ} \mathrm{C}$ to $60^{\circ} \mathrm{C}$. DSV is a powerful technique to predict the relative molecular size of polymers. To the best of our knowledge, this work is the first comprehensive work towards using DSV, at different temperatures, to differentiate between physical and chemical blocking of disulfide interchange reaction. 


\section{MATERIALS AND METHODS}

\subsection{Materials.}

BiPro, a commercial whey protein isolate (WPI) produced by Davisco Food International (LeSueur, Mn, USA) was used. Powder composition was $94 \%$ protein, $5 \%$ moisture and 1\% ash, all by weight. Dithiothreitol (DTT) was obtained from Fisher Chemical Co. (NJ, USA). Distilled water of total dissolved solids of 25 PPM was used in all the experiments.

\subsection{Preparation of Protein Solution.}

The protein solution was prepared by dissolving the native protein powder in distilled water by gentle magnetic stirring for 30 minutes. Protein concentration was adjusted to $5 \%$ or $3 \% \mathrm{w} / \mathrm{w}$. The $\mathrm{pH}$ value of protein solution was recorded to be $6.8 \mathrm{pH}$ adjustment was done using $0.1 \mathrm{~N} \mathrm{HCl}$ to reach $\mathrm{pH} 3$, when needed. Thermal treatment of the protein solution was carried out by heating at $80^{\circ} \mathrm{C}$ for $1 \mathrm{hr}$ to denature the protein and to induce chemical and physical bonds, then cooling to $6^{\circ} \mathrm{C}$ and maintaining at $6^{\circ} \mathrm{C}$ for $24 \mathrm{hrs}$.

\subsection{Dilute Solution Viscometry (DSV).}

Cannon Fenske dilution glass capillary viscometer (part \# 9722-L50, Cannon Instruments, State College, PA, USA) was used for DSV measurements according to the method explained in [5] and [6]. A water bath was used to control the temperature in the range from $30^{\circ} \mathrm{C}$ to $60^{\circ} \mathrm{C}\left( \pm 0.05^{\circ} \mathrm{C}\right)$. The original protein solution $(3 \% \mathrm{w} / \mathrm{w})$ was diluted to a range of concentrations from 0.67 to $3 \mathrm{~g} /$ d1. The efflux flow time for all solutions was more than 280 s. Experiments were done in triplicates.

\section{RESULTS AND DISCUSSION}

\subsection{Intrinsic Viscosity}

DSV is a useful tool in investigating the molecular properties of the food polymers [7] and biological macro- molecules [8]. Not only food polymers, but synthetic polymer characterization is extensively done using intrinsic viscosity measurements [9].

The intrinsic viscosity is defined as:

$$
[\eta]=\lim _{c \rightarrow 0} \frac{\eta_{s p}}{c}=\lim _{c \rightarrow 0} \frac{\eta_{r}-1}{c}
$$

Where $[\eta], \eta_{\mathrm{sp}}, \eta_{\mathrm{r}}$ and $\mathrm{c}$ are the intrinsic viscosity, specific viscosity, relative viscosity and concentration, respectively.

Extrapolation of $\frac{\eta_{s p}}{c}$ (reduced viscosity) to zero concentration determines $[\eta]$ based on the above Eq (1). In the dilute concentrations conditions, the dependence is linear and can be written as the Huggins equation:

$$
\frac{\eta_{s p}}{c}=[\eta]+k_{H}[\eta]^{2} c
$$

where $k_{H}$ is the (dimensionless) Huggins constant.

Intrinsic viscosity is measured for very dilute solutions, and hence it indicates the relative polymer's molecular size and shape.

DSV has been extensively used with native and polymerized whey proteins to investigate their molecular properties [10]-[12] at room temperature $\left(25\right.$ and $\left.30^{\circ} \mathrm{C}\right)$. However, DSV measurements of whey protein polymers at higher temperatures are scarce in literature [13]. Tables 1 and 2 and Figure 1 show the DSV data for whey protein aggregates resulting from thermal treatment at two conditions; the first condition is $3 \% \mathrm{WPI}$ at $\mathrm{pH} 7$ in the presence of $1 \%$ DTT, hereafter termed (with DTT), while the second condition is $5 \%$ at $\mathrm{pH} 3$ without DTT, hereafter termed (at $\mathrm{pH} 3$ ). The reason of choosing lower concentration with DTT is that at higher concentrations ( $\sim 5 \%$ and higher), the solution gels. Table 3 shows that the value of intrinsic viscosity with DTT is higher than at $\mathrm{pH} 3$ despite the higher initial concentration at $\mathrm{pH}$ 3. This observation indicates that the aggregation mechanism with DTT yields higher aggregate size than at $\mathrm{pH}$ 3. It is worth mentioning that using DTT breaks the intramolecular disulfide link and prevents that formation of the new intermolecular ones, however, at

Table 1 Data of specific viscosities $\left[\eta_{s p}\right]$ and standard deviation $\sigma(\%)$ for aggregated proteins at $\mathrm{pH} 3$.

\begin{tabular}{|c|c|c|c|c|c|c|c|c|}
\hline Conc. $(\mathrm{g} / \mathrm{dl})$ & \multicolumn{2}{|c|}{$30^{\circ} \mathrm{C}$} & \multicolumn{2}{c|}{$40^{\circ} \mathrm{C}$} & \multicolumn{3}{c|}{$50^{\circ} \mathrm{C}$} & \multicolumn{2}{c|}{$\mathrm{C}$} \\
\hline & {$\left[\eta_{\mathrm{sp}}\right]$} & $\sigma(\%)$ & {$\left[\eta_{\mathrm{sp}}\right]$} & $\sigma(\%)$ & {$\left[\eta_{\mathrm{sp}}\right]$} & $\sigma(\%)$ & {$\left[\eta_{\mathrm{sp}}\right]$} & $\sigma(\%)$ \\
\hline 2 & 0.45 & 2.23 & 0.41 & 0.19 & 0.39 & 1.27 & 0.37 & 0.77 \\
\hline 1.33 & 0.29 & 0.23 & 0.28 & 0.38 & 0.25 & 3.01 & 0.23 & 0.82 \\
\hline 1. & 0.21 & 0.86 & 0.20 & 0.68 & 0.18 & 0.40 & 0.18 & 1.54 \\
\hline 0.8 & 0.17 & 0.46 & 0.16 & 0.94 & 0.15 & 0.55 & 0.14 & 0.15 \\
\hline 0.67 & 0.14 & 0.83 & 0.13 & 0.20 & 0.12 & 0.55 & 0.11 & 0.56 \\
\hline
\end{tabular}


Table 2 Data of specific viscosities $\left[\eta_{s p}\right]$ and standard deviation $\sigma(\%)$ for proteins with DTT.

\begin{tabular}{|c|c|c|c|c|c|c|c|c|}
\hline Conc. $(\mathrm{g} / \mathrm{dl})$ & \multicolumn{3}{|c|}{$30^{\circ} \mathrm{C}$} & \multicolumn{2}{c|}{$40^{\circ} \mathrm{C}$} & \multicolumn{3}{c|}{$50^{\circ} \mathrm{C}$} \\
\hline & {$\left[\eta_{\mathrm{sp}}\right]$} & $\sigma(\%)$ & {$\left[\eta_{\mathrm{sp}}\right]$} & $\sigma(\%)$ & {$\left[\eta_{\mathrm{sp}}\right]$} & $\sigma(\%)$ & {$\left[\eta_{\mathrm{sp}}\right]$} & $\sigma(\%)$ \\
\hline 3 & 7.87 & 0.13 & 9.24 & 0.06 & 8.73 & 6.70 & 6.83 & 2.03 \\
\hline 2 & 3.43 & 5.18 & 3.49 & 0.00 & 3.31 & 4.46 & 3.35 & 3.44 \\
\hline 1.5 & 1.91 & 2.44 & 1.94 & 0.19 & 2.06 & 1.70 & 2.12 & 1.96 \\
\hline 1.2 & 1.36 & 1.80 & 1.44 & 0.55 & 1.61 & 1.12 & 1.33 & 0.58 \\
\hline 1 & 1.03 & 1.89 & 1.06 & 2.17 & 1.20 & 0.69 & 1.06 & 1.76 \\
\hline
\end{tabular}

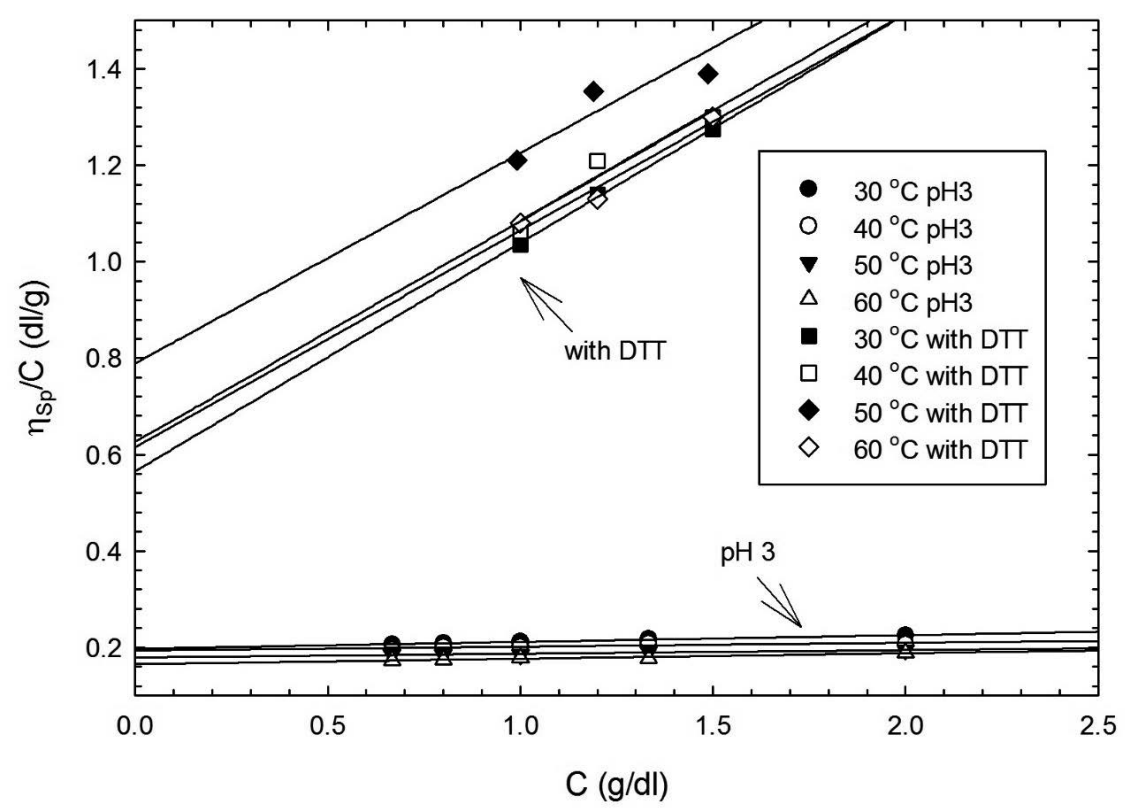

Fig. 1 Reduced viscosity of dilute solutions of whey protein aggregates at $\mathrm{pH} 3$ and with DTT as a function of protein concentration at different temperatures.

$\mathrm{pH} 3$, intramolecular disulfide links are not affected and only the intermolecular ones are being hindered. The aggregate size with DTT is higher, probably due to the more open structure of the molecules, caused by the cleaved intramolecular disulfide bonds. The more open structure causes more intermolecular hydrogen bonds and hydrophobic interactions and hence larger aggregates.

\subsection{Huggins Constant and Chain Conformation}

Useful information about the polymers confirmation can be obtained by determining Huggins constant. A comprehensive literature survey of $k_{H}$ values for different systems was done by [14].

$k_{H}$ values of flexible polymer chains are in the range of $\sim 0.2-0.8$; typically around 0.3 in good solvents [15].

Figure 1 show a remarkable difference in lines slopes, where aggregates with DTT having much steeper slopes, reflecting higher values of Huggins constant as com- pared with $\mathrm{pH}$ 3. Table 3 shows the values of Huggins constants. The high values of Huggins constants with DTT suggest collapsed, aggregated molecular structure, while the values at $\mathrm{pH} 3$ suggest wormlike chains ranging from the coil limit to the rod limit. The collapsed aggregated molecular structure with DTT is probably due to the more open structure, causing higher population of hydrophobic interactions and hydrogen bonding.

\subsection{Voluminosity}

Voluminosity $V_{E}$ of protein polymer solutions was determined by extrapolating $\mathrm{Y}$ - (defined by equation 3 ) versus protein concentration $(\mathrm{C}, \mathrm{g} / \mathrm{dl})$ - to zero concentration. [16]

$$
Y=\frac{\left(\eta r^{0.5}-0.1\right)}{c\left(1.35 \eta r^{0.5}-0.1\right)}
$$

Voluminosity indicates the volume of the polymer molecules that are solvated in certain solvent. We clearly see from Figure 2 that $V_{E}$ is appreciably higher in case of 
Table 3 Comparison between intrinsic viscosity, $\mathrm{k}_{\mathrm{H}}$ and shape factor of aggregated proteins at $\mathrm{pH} 3$ and with DTT.

\begin{tabular}{|c|c|c|c|c|c|c|}
\hline Temperature $\left({ }^{\circ} \mathrm{C}\right)$ & \multicolumn{2}{|c|}{ Intrinsic Viscosity $[\eta] \mathrm{dl} / \mathrm{g}$} & \multicolumn{2}{|c|}{$\mathrm{k}_{\mathrm{H}}$} & \multicolumn{2}{c|}{ Shape Factor $(\nu)$} \\
\hline & With DTT & at $\mathrm{pH} 3$ & With DTT & at $\mathrm{pH} 3$ & With DTT & at $\mathrm{pH} 3$ \\
\hline 30 & 0.56 & 0.197 & 1.5 & 0.359 & 2.12 & 2.52 \\
\hline 40 & 0.62 & 0.194 & 1.2 & 0.213 & 2.31 & 2.55 \\
\hline 50 & 0.79 & 0.180 & 0.71 & 0.239 & 2.74 & 2.53 \\
\hline 60 & 0.625 & 0.165 & 1.17 & 0.420 & 2.26 & 2.50 \\
\hline
\end{tabular}

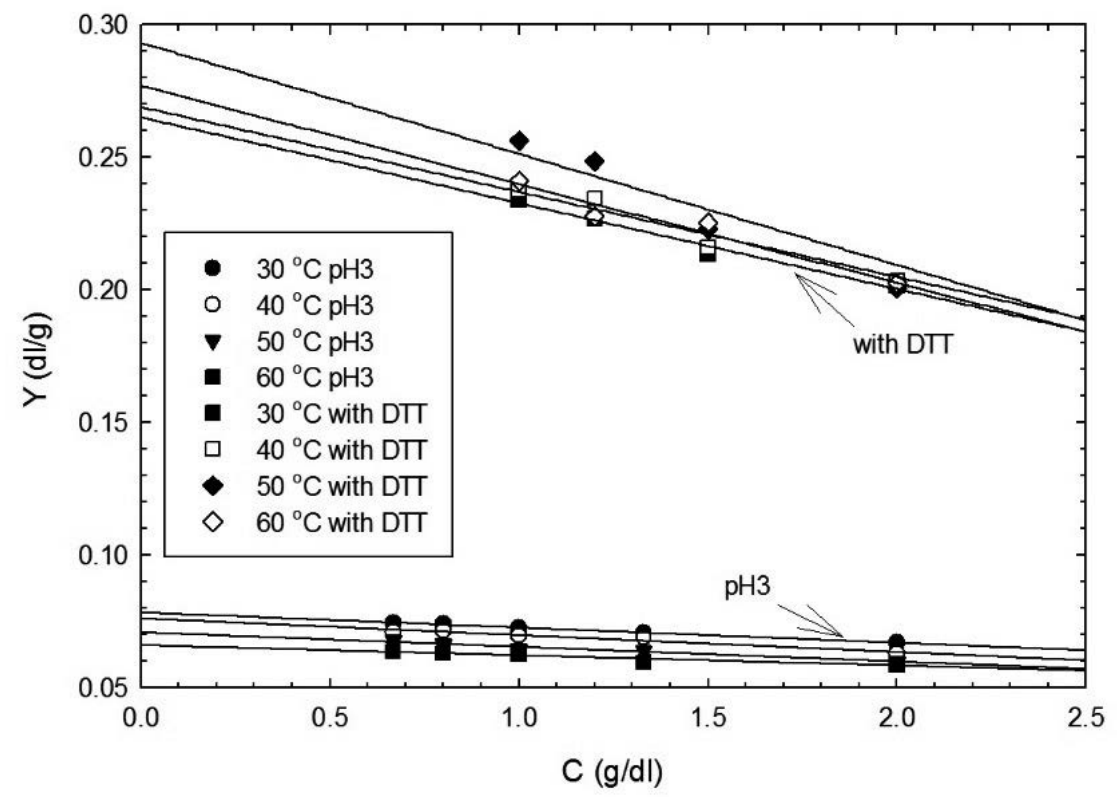

Fig. 2 Determination of voluminosity of dilute solutions of whey protein aggregates at different temperatures.

samples with DTT. The observation indicates higher solvated volume in case of using DTT as compared with $\mathrm{pH}$ 3 , although the initial concentration of samples at $\mathrm{pH} 3$ was higher than samples with DTT. This finding confirms the observation that aggregates with DTT possess more open structure and hence larger volume, due to the higher population of physical bonds due to availability of the interior surface.

\section{Shape factor}

Shape factor $\nu$ is determined to investigate the shape of the protein aggregated molecules. The shape factor of the molecules can be determined from the following correlation (Harding 1998):

$$
[\eta]=\nu V_{E}
$$

Table 3 shows the values of $\nu$ at different temperatures. We clearly see that the shape factors with DTT and at $\mathrm{pH}$ 3 are similar. At both conditions, the molecules are close to be spherical, with a shape factor around 2.5 . This observation indicates that the overall shape of the macromolecules is not affected by the means of aggregation. A previous publication [13] showed that whey protein polymers, containing disulfide bonds, at pH 7 are also spherical in shape, indicating that whey protein polymers and aggregate are spherical in shape over a wide range of polymerization/aggregation conditions.

\section{Conclusions}

Thermal aggregation of whey proteins proceeds differently when blocking disulfide bonds chemically as compared with physical blocking. Chemical blocking produces larger spherical, with collapsed, aggregated molecular structure, while physical aggregation produces smaller spherical wormlike chains. 


\section{References}

1) K. Shimada and J. Cheftel, "Sulfhydryl group/disulfide bond interchange reactions during heat-induced gelation of whey protein isolate," J. Agric. Food Chem., vol. 37, no. 1, pp. 161168, 1989.

2) S. F. Betz, "Disulfide bonds and the stability of globular proteins.," Protein Sci., vol. 2, no. 10, pp. 1551-1558, 1993.

3) W. J. Wedemeyer, E. Welker, M. Narayan, and H. a Scheraga, "Disulfide Bonds and Protein Folding," Biochem. Curr. Top., vol. 39, no. 15, pp. 4207-4216, 2000.

4) A. S. Eissa, "Enzymaticmodification ofwhey protein gels at low pH,” North Carolina State University, 2005.

5) M. G. Neira-Velazquez, M. T. RodrıguezHernandez, E. Hernandez-Hernandez, and A. R. Y. Ruiz-Martınez, "Polymer molecular weight measurement," in Handbook of Polymer Synthesis, Characterization, and Processing, E. Saldivar-Guerra and E. Vivaldo-Lima, Eds. Wiley Interscience., 2013.

6) B. Vardhanabhuti and E. A. Foegeding, "Rheological Properties and Characterization of Polymerized Whey Protein Isolates," J. Agric. Food Chem., vol. 47, no. 9, pp. 3649-3655, 1999.

7) J. J. Resch and C. R. Daubert, "Rheological and physicochemical properties of derivatized whey protein concentrate powder," Int. J. Food Prop., vol. 5, no. 2, pp. 419-434., 2002.

8) S. E. Harding, "Dilute solution viscometry of food biopolymers," in Functional properties of food macromolecules, S. E. Hill and R. G. Mitchel, Eds. Aspen, 1998.
9) H. G. Elias, Macromolecules. Plenum Press., 1977.

10) M. Britten and H. Giroux, "Acid-induced gelation of whey protein polymers : effects of $\mathrm{pH}$ and calcium concentration during polymerization," Food Hydrocolloids, vol. 15, pp. 609617, 2001.

11) C. R. Daubert, H. M. Hudson, E. A. Foegeding, and P. Prabhasankar, "Rheological characterization and electrokinetic phenomena of charged whey protein dispersions of defined sizes," LWT - Food Sci. Technol., vol. 39, no. 3, pp. 206-215, 2006.

12) N. Purwanti, M. Smiddy, A. Jan, V. Der Goot, and R. De Vries, "Food Hydrocolloids Modulation of rheological properties by heat-induced aggregation of whey protein solution," Food Hydrocolloids, vol. 25, no. 6, pp. 1482-1489, 2011.

13) A. S. Eissa, "Newtonian viscosity behavior of dilute solutions of polymerized whey proteins. Would viscosity measurements reveal more detailed molecular properties?," Food Hydrocolloids, vol. 30, no. 1, pp. 200-205, Jan. 2013.

14) F. Billmeyer, Textbook of polymer science. New York: Wiley Interscience, 1984.

15) R. Pamies, J. G. Hernández Cifre, M. del Carmen López Martínez, and J. García de la Torre, "Determination of intrinsic viscosities of macromolecules and nanoparticles. Comparison of single-point and dilution procedures," Colloid Polym. Sci., vol. 286, no. 11, pp. 1223-1231, Jul. 2008.

16) R. Simba, "The Influence of Brownian Movement on the Viscosity of Solutions," J. Phys. Chem., vol. 44, no. 1, pp. 25-34, 1940. 